\title{
Surface expression of phosphatidylserine on macrophages is required for phagocytosis of apoptotic thymocytes
}

\author{
MK Callahan ${ }^{1}$, P Williamson $^{2}$ and RA Schlegel ${ }^{*, 1}$ \\ 1 Department of Biochemistry and Molecular Biology, Penn State University, \\ University Park, PA 16802 USA \\ 2 Department of Biology, Amherst College, Amherst, MA 01002 USA \\ * Corresponding author: RA Schlegel, Department of Biochemistry and \\ Molecular Biology, 428 South Frear Laboratory, Penn State University, \\ University Park, PA 16802 USA. Tel: 814 865-6974; Fax: 814 863-7024; \\ E-mail: ur3@psu.edu
}

Received 15.10.99; revised 12.2.00; accepted 6.3.00

Edited by BA Osborne

\begin{abstract}
Cells generally maintain an asymmetric distribution of phospholipids across the plasma membrane bilayer, restricting the phospholipid, phosphatidylserine (PS), to the inner leaflet of the plasma membrane. When cells undergo apoptosis, this asymmetric transbilayer distribution is lost, bringing PS to the surface where it acts as a signal for engulfment by phagocytes. The fluorescent dye merocyanine 540 specifically stains the plasma membrane of apoptotic cells which have lost their asymmetric distribution of phospholipids. However, it also stains non-apoptotic macrophages, suggesting that phospholipid asymmetry may not be maintained in these cells, and thus that they may express PS on their surface. Here, the PS-binding protein, annexin V, was used to show that in fact normal macrophages do express PS on their surface. Furthermore, pre-treating macrophages with annexin V was found to inhibit phagocytosis of apoptotic thymocytes and thymocytes on which PS expression was artificially induced, but did not inhibit phagocytosis of latex beads or Fc receptor-mediated phagocytosis of opsonized erythrocytes. These results indicate that PS is constitutively expressed on the surface of macrophages and is functionally significant for the phagocytosis of PS-expressing target cells. Cell Death and Differentiation (2000) 7, 645-653.
\end{abstract}

Keywords: macrophages; phagocytosis; membrane asymmetry; phosphatidylserine; annexin V; T lymphocytes; apoptosis

Abbreviations: PS, phosphatidylserine; PBS, phosphate-buffered saline; FBS, fetal bovine serum; RPMI, Roswell Park Memorial Institute; GlcNAc, N-acetylglucosamine; MC540, merocyanine 540

\section{Introduction}

A crucial step in programmed cell death, or apoptosis, is recognition and phagocytosis of the dying cell by neighboring cells or professional phagocytes. ${ }^{1}$ Engulfment before cell lysis prevents the inflammation which might ensue from release of the cell's intracellular contents. ${ }^{1,2}$ In order for apoptotic cells to be distinguished from their healthy neighbors, the apoptotic cell surface must be recognizably different from that of nonapoptotic cells. The expression of the membrane phospholipid, phosphatidylserine (PS), on the cell surface is one signal which identifies cells as apoptotic., ${ }^{3,4}$ The importance of this surface PS for recognition is demonstrated by the finding that masking PS on the surface of apoptotic cells with the PSspecific binding protein, annexin $\mathrm{V}$, specifically reduces their phagocytosis. ${ }^{5,6}$

In the specific case of recognition of apoptotic lymphocytes by macrophages, two different PS-dependent recognition systems operate. ${ }^{7}$ One system is utilized by unactivated macrophages such as mouse bone marrow macrophages, human monocyte-derived macrophages and the murine macrophage cell line J774. Phagocytosis using this system is inhibited by erythrocytes lysed and resealed under conditions where PS becomes exposed on the cell surface. ${ }^{8}$ Phagocytosis of these PS-presenting (lipidsymmetric) erythrocytes, but not of apoptotic thymocytes, is completely inhibited by PS vesicles. ${ }^{9}$ Phagocytosis using the other system, utilized by activated macrophages such as mouse peritoneal macrophages and $\beta$-glucan-activated mouse bone marrow macrophages, is inhibitable by PS vesicles, but not by lipid-symmetric erythrocytes. ${ }^{8}$ Phagocytosis by both systems, however, is inhibited by annexin $\mathrm{V}^{6}$

The two macrophage recognition systems are also distinguished by their different sensitivities to other inhibitors. The synthetic peptide RGDS and antibodies to the vitronectin receptor inhibit phagocytosis of apoptotic lymphocytes by unactivated macrophages, ${ }^{7,8}$ implicating this integrin in recognition, whereas $\mathrm{N}$-acetylglucosamine (GlcNAc) inhibits phagocytosis by activated macrophages, implicating a lectin-like receptor in recognition. ${ }^{8,10}$ Phagocytosis by both recognition systems is inhibited by treating macrophages with antibodies to the lipoprotein receptor CD36 ${ }^{11}$ and to the lipopolysaccharide receptor CD14. ${ }^{12,13}$ However, the ligands which any of the receptors may recognize on the apoptotic cell surface have yet to be identified. In contrast, ICAM-3 on the lymphocyte surface participates in the interaction of apoptotic lymphocytes and unactivated macrophages, although the receptor with which ICAM-3 interacts has not been identified. ${ }^{14}$

Normal, healthy cells sequester PS to the inner leaflet of the bilayer. ${ }^{4,15}$ During the course of apoptosis, however, PS equilibrates between the two leaflets ${ }^{16}$ resulting in exposure of PS on the cell surface. ${ }^{3,4}$ Before the development of annexin $\mathrm{V}$ as a tool to detect PS exposed on the apoptotic cell surface resulting from loss of membrane asymmetry, ${ }^{17}$ the membrane probe merocyanine 540 (MC540) was utilized for that purpose. MC540 is a fluorescent dye sensitive to lipid packing, ${ }^{18}$ which binds to cells in which membrane asymmetry has been lost. ${ }^{19,20}$ Although normal lymphocytes, monocytes and neutrophils do not bind the 
dye ${ }^{21}$ apoptotic lymphocytes are readily distinguished by their increased fluorescence following staining with MC540. 3,22,23 Surprisingly, primary macrophages and macrophage cell lines stain with MC540. ${ }^{24}$ This result suggests that normal, non-apoptotic macrophages do not maintain the same scrupulously asymmetric distribution of phospholipids that other cells do, and thus may express PS on their surface. The studies presented here demonstrate that normal macrophages do indeed express PS on their surface, and that expression of PS on the macrophage surface is specifically involved in the engulfment of PSexposing target cells.

\section{Results}

To investigate whether normal, non-apoptotic macrophages express PS on their surface, adherent J774 macrophages were stained with the PS-specific probe, fluorescent annexin $\mathrm{V}$, and examined by fluorescence microscopy. Because of the prodigious rate of membrane internalization and recycling characteristic of macrophages, staining was performed at $4{ }^{\circ} \mathrm{C}$ to slow these processes. As shown in Figure 1A, macrophages do stain with annexin $\mathrm{V}$. Although plasma membrane staining predominates, nuclei can be discerned in the cells, outlined by annexin $\mathrm{V}$ internalized during the staining procedure. This result is consistent with the previous report that the plasma membrane of normal macrophages labeled with MC540 is very rapidly internalized. ${ }^{24}$ To confirm that any annexin $\mathrm{V}$ internalized was bound to the plasma membrane, and not simply taken up directly from solution, macrophages were stained with annexin $\mathrm{V}$ in the presence or absence of $\mathrm{Ca}^{2+}$. Because binding of annexin $\mathrm{V}$ to $\mathrm{PS}$ is $\mathrm{Ca}^{2+}$-dependent, staining in the absence of $\mathrm{Ca}^{2+}$ should reflect fluid-phase internalization. As shown in Figure 2A, annexin $\mathrm{V}$ staining of $\mathrm{J} 774$ macrophages in the presence of $\mathrm{Ca}^{2+}$ is significantly higher than in its absence, indicating that staining in the presence of $\mathrm{Ca}^{2+}$ is predominantly plasma membrane staining. That such staining is not restricted to cell lines or to just unactivated macrophages is also shown in Figure $2 \mathrm{~A}$ where activated, elicited peritoneal macrophages are seen to stain with annexin $\mathrm{V}$. The expression of PS on the surface of macrophages raises the question of whether it plays a functional role in recognition and phagocytosis of apoptotic cells.

As reported previously, pre-treating apoptotic thymocytes with annexin $\mathrm{V}$ significantly inhibits their phagocytosis by macrophages. ${ }^{6}$ In those studies, however, treated thymocytes were not washed free of excess, soluble annexin $\mathrm{V}$ before presentation to macrophages. In light of the fact that macrophages express PS on their surface, it is possible that in those experiments excess annexin $V$, carried over with the target cells, might be acting at the macrophage surface. This possibility was tested by pretreating target cells with annexin $\mathrm{V}$, washing to remove unbound annexin $\mathrm{V}$ and then presenting the treated cells to macrophages. The targets used were D011.10 cells, an ovalbumin-specific murine $\mathrm{T}$ cell hybridoma, which can be induced by a variety of agents to undergo apoptosis and expose PS. ${ }^{16,25}$ As with all cell populations, induction of apoptosis in DO11.10 cells is not synchronous and at any a

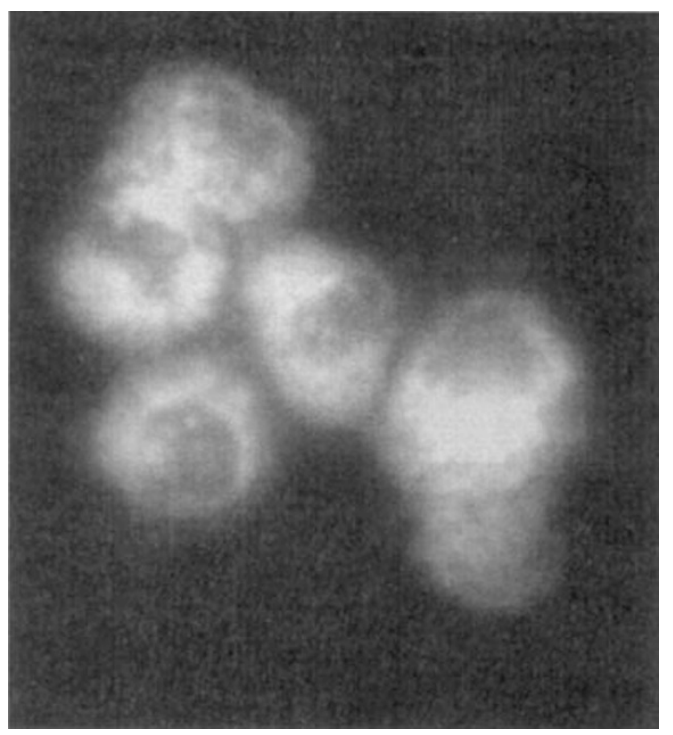

b

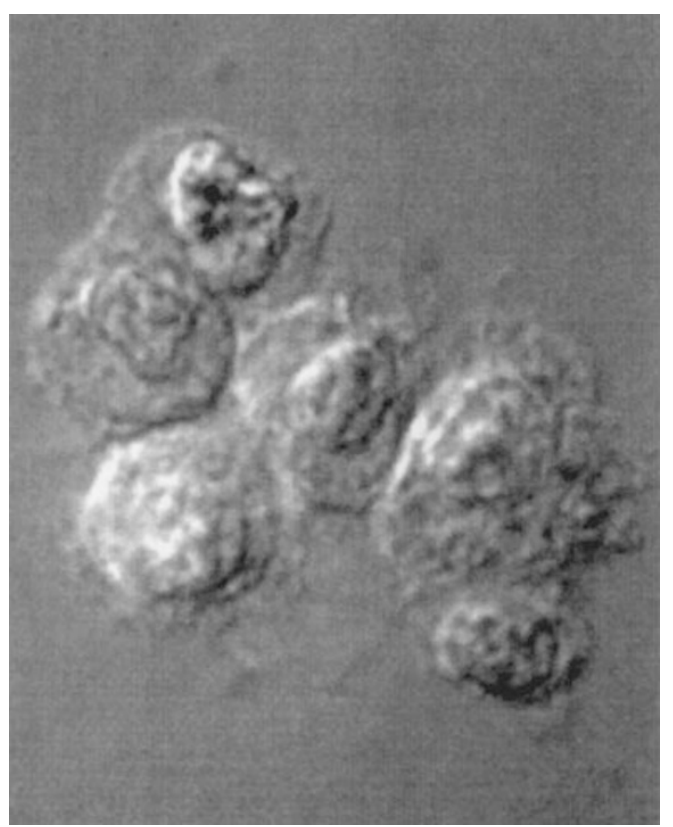

Figure 1 Detection by microscopy of fluorescent annexin $\mathrm{V}$ binding to $\mathrm{J774}$ macrophages. Monolayer cultures of $\mathrm{J} 774$ macrophages were stained with fluorescent annexin V, fixed and photographed using fluorescence (A) or Nomarski (B) optics. The data presented are representative of two separate experiments with similar results

given timepoint only a small fraction of intact cells expose PS. However, a uniform population of PS-expressing cells can be produced by elevating cytosolic $\mathrm{Ca}^{2+}$ concentrations with the $\mathrm{Ca}^{2+}$ ionophore A23187. This treatment activates a non-specific lipid flipsite, termed the scramblase, also activated by the apoptotic program, that allows rapid diffusion of $P S$ to the cell surface. ${ }^{25}$ To facilitate initial studies identifying the site at which annexin $\mathrm{V}$ works, these ionophore-treated cells were used as targets. 


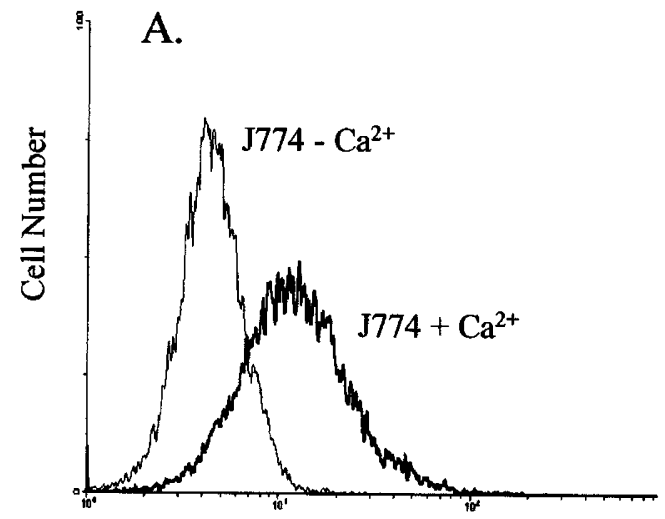

Fluorescence intensity

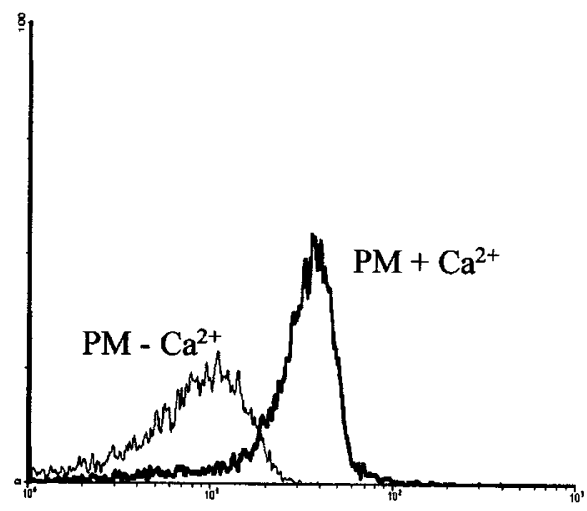

Fluorescence intensity

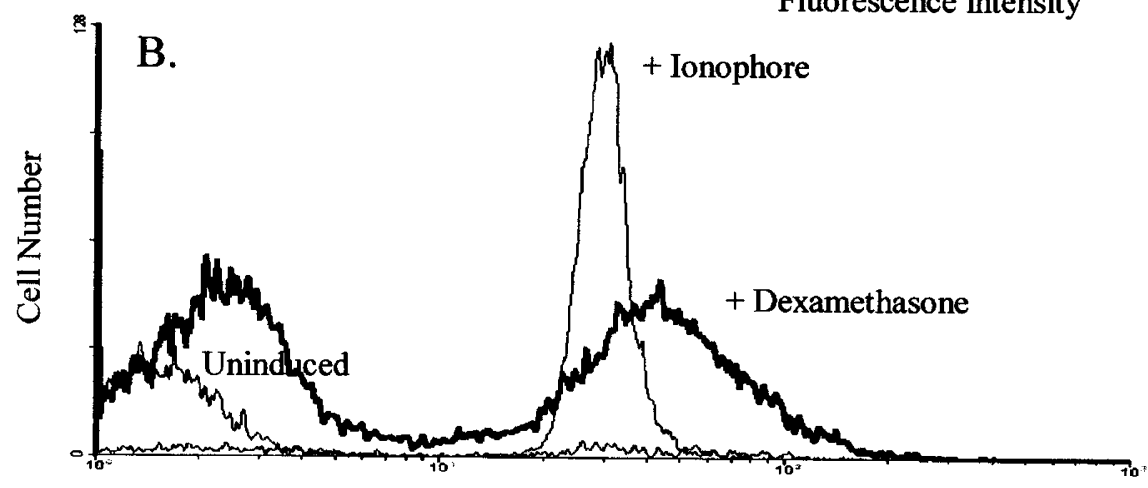

Fluorescence intensity

Figure 2 Flow cytometric detection of fluorescent annexin V binding to macrophages and DO11.10 target cells. (A) Either J774 or elicited peritoneal macrophages (PM) released from monolayer were stained with fluorescent annexin $\mathrm{V}$ in the presence or absence of $\mathrm{Ca}^{2+}$ and analyzed by flow cytometry. (B) DO11.10 cells incubated with or without $\mathrm{Ca}^{2+}$ ionophore in the presence of $\mathrm{Ca}^{2+}$, or induced to undergo apoptosis by dexamethasone, were stained with fluorescent annexin $\mathrm{V}$, and analyzed by flow cytometry. In both (A) and (B), cells stained with propidium iodide were gated out and do not appear in the profiles. The data presented are representative of three separate experiments with similar results

As shown in Figure 2B, virtually all DO11.10 cells treated for 10 min with $\mathrm{Ca}^{2+}$ ionophore expose PS on their surface as detected by staining with fluorescent annexin $\mathrm{V}$; the staining of cells induced with dexamethasone to undergo apoptosis is shown for comparison. As shown previously, cells induced by ionophore to expose PS are phagocytosed in the same PS-dependent fashion as cells in which PS is exposed as part of the apoptotic program. ${ }^{25}$ Phagocytosis of these cells by $\mathrm{J} 774$ macrophages is reduced about fourfold by pretreating them with $10 \mu \mathrm{M}$ annexin $\mathrm{V}$, and, importantly, the extent of inhibition was not affected by washing the targets to remove excess annexin $\mathrm{V}$ before presenting them to macrophages (data not shown), verifying that the PS exposed on target cells is required for their phagocytosis.

As well as confirming that masking PS on the target cell surface blocks phagocytosis, the above results provide protocols for asking whether the PS exposed at the macrophage surface plays any role in phagocytic clearance. To address this question, targets, macrophages or both were pre-treated with annexin $V$ and washed, then the targets and macrophages combined and phagocytosis measured. As shown in Figure 3, phagocytosis was inhibited to a similar extent (approximately 80\%) regard- less of whether targets or macrophages were pre-treated with annexin V. Additionally, inhibition produced by treating both target and macrophage with annexin $V$ (without washing) was statistically indistinguishable from treating either just targets or just macrophages alone. These results imply that the PS exposed on the macrophage surface is required for phagocytosis of PS-expressing target cells.

Previous studies demonstrated that the concentration of fluorescent annexin $\mathrm{V}$ required for maximal binding to apoptotic cells was similar to the concentration which produced maximal inhibition of phagocytosis, ${ }^{6}$ as expected if inhibition is the result of high affinity specific binding of annexin V to PS on the target cell surface. If inhibition at the macrophage surface also is the direct result of specific high affinity binding and masking of PS, versus some nonspecific effect at the cell surface, the dose-response for annexin $\mathrm{V}$ inhibition might be expected to be similar for treatment of either cell type. In fact, inhibition at the target cell surface was near maximal at $0.1 \mu \mathrm{M}$ annexin $\mathrm{V}$, with only slight increases at higher concentrations; similarly, annexin $\mathrm{V}$ pre-treatment of macrophages inhibited phagocytosis with a maximal effect near $0.1 \mu \mathrm{M}$ annexin $\mathrm{V}$ (data not shown). This result implies that the effects of annexin $V$ on macrophages result from the same high affinity binding 


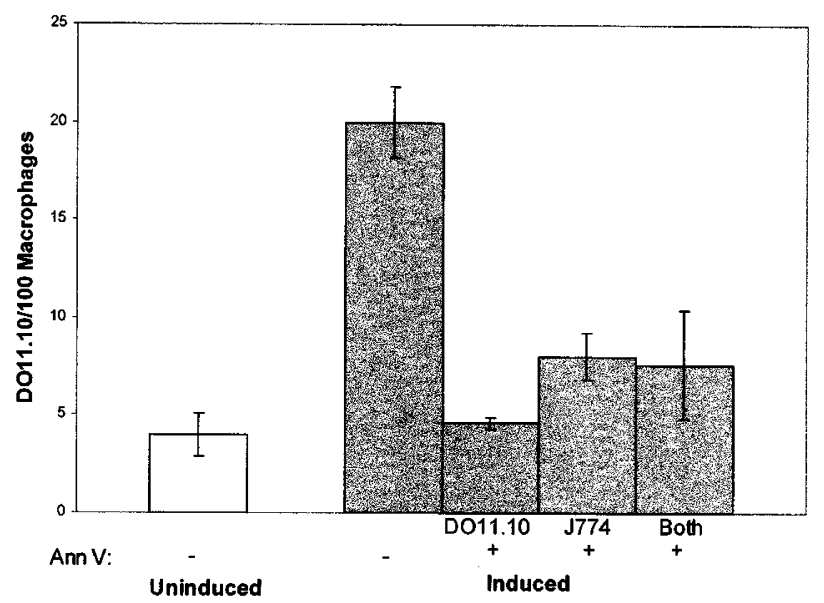

Figure 3 Phagocytosis following pre-treatment of D011.10 targets, J774 macrophages, or both cell types with annexin V. D011.10 cells were induced to express PS by incubating with $\mathrm{Ca}^{2+}$ ionophore in the presence of $\mathrm{Ca}^{2+}$. These targets, J774 macrophages, or both cell types were pre-treated with $10 \mu \mathrm{M}$ annexin $\mathrm{V}$ (Ann V) before presenting the targets to macrophages. When only one cell type was pre-treated, cells were washed before targets were presented to macrophages. Phagocytosis of uninduced D011.10 cells is shown for comparison. The data presented are representative of three separate experiments with similar results

as its effects on targets, identifying PS as the target of its action.

While these experiments rule out the possibility of nonspecific binding as the mechanism of annexin $\mathrm{V}$ effects on macrophages, they leave open the possibility that this specific binding might non-specifically inhibit phagocytosis, i.e., that annexin $\mathrm{V}$ might inhibit phagocytosis in general by interfering with a membrane process (such as membrane bending or fusion) required for phagocytosis. This possibility was tested by asking whether annexin $V$ treatment of macrophages prevented uptake of targets which do not present PS. As shown in Figure 4A, treating macrophages with annexin $\mathrm{V}$ did not inhibit the phagocytosis of fluorescent latex beads. Nor, as shown in Figure 4B, was the Fc-mediated phagocytosis of opsonized erythrocytes impaired by treatment with annexin V. Thus, the inhibition by annexin $V$ at the macrophage surface is specific to PS-presenting targets and is not a non-specific consequence of interference with general phagocytic processes of the cell.

As indicated in the Introduction, and shown in Figure 5A, $\mathrm{J} 774$ macrophages behave as unactivated macrophages in that phagocytosis of PS-presenting cells is inhibited by RGDS and not by PS vesicles or GIcNAc which inhibit phagocytosis by activated macrophages. ${ }^{8}$ When primary unactivated macrophages ingest $\beta$-glucan particles, they acquire the activated macrophage recognition system. ${ }^{26}$ To determine whether the same was true for the $\mathrm{J} 774$ cell line, cultures were incubated with $\beta$-glucan for $\geqslant 3$ days, and then phagocytosis was measured in the presence of a variety of inhibitors. As shown in Figure $5 \mathrm{~B}$, after $\beta$-glucan treatment, phagocytosis by $\mathrm{J} 774$ macrophages became sensitive to the presence of either PS vesicles or GIcNAc. In contrast to the case of primary macrophages activated

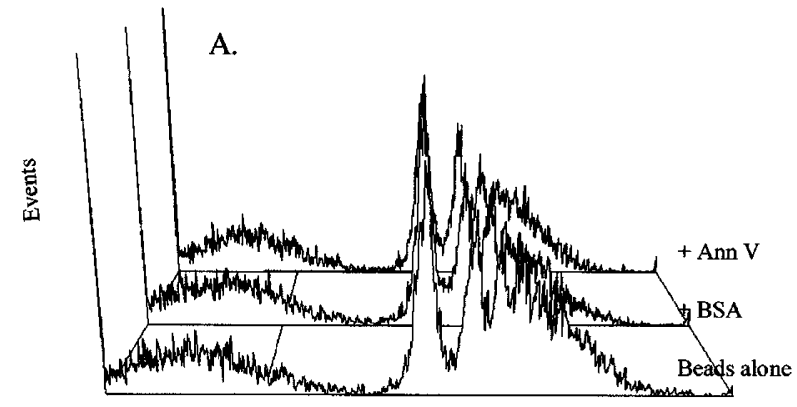

Fluorescence intensity

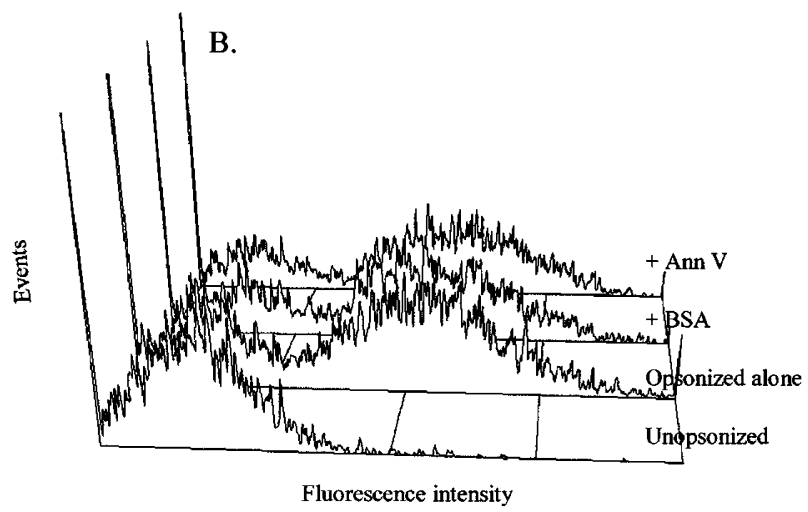

Figure 4 Phagocytosis of latex beads and Fc-mediated phagocytosis by macrophages pre-treated with annexin V. (A) Fluorescent latex beads were added to adherent $\mathrm{J} 774$ macrophages that were pre-treated with BSA or annexin V (Ann V). After $30 \mathrm{~min}$, cells were released from culture dishes and analyzed by flow cytometry. The broad peak of low fluorescence represents cells which have not phagocytosed beads. The sharp positive peaks represent macrophages that have phagocytosed increasing numbers of beads. The data presented are representative of three separate experiments with similar results. (B) Fluorescently-labeled erythrocytes opsonized with anti-glycophorin antibody were added to $\mathrm{J} 774$ macrophages that were pre-treated with BSA or annexin V (Ann V). After $30 \mathrm{~min}$, uningested erythrocytes were lysed with $\mathrm{NH}_{4} \mathrm{Cl}$, and the macrophages were analyzed by flow cytometry. Phagocytosis of un-opsonized erythrocytes is shown for comparison. The data presented are representative of four separate experiments with similar results

by $\beta$-glucan, however, phagocytosis by activated $\mathrm{J} 774$ cells remained sensitive to RGDS, a point considered further in the Discussion. To determine whether activated J774 macrophages, like their unactivated counterparts, require PS on their surface for phagocytosis, the experiment described for Figure 3 was repeated with $\beta$-glucanactivated J774 macrophages. As shown in Figure 6, the results were similar to those obtained with unactivated cells: phagocytosis of PS-presenting DO11.10 cells was inhibited to a similar extent regardless of whether target, phagocyte, or both, were pre-treated with annexin V. Thus, the dependence of phagocytosis on PS expressed on the macrophage surface is not confined to unactivated macrophages.

In these model experiments, both targets and phagocytes were cell lines, and the exposure of PS on target cells was artificially induced. Even though the phagocytosis of these cells requires the same integrin and/or lectin receptors, as well as PS, that are required for phagocytosis of true apoptotic cells, experiments were carried out with 

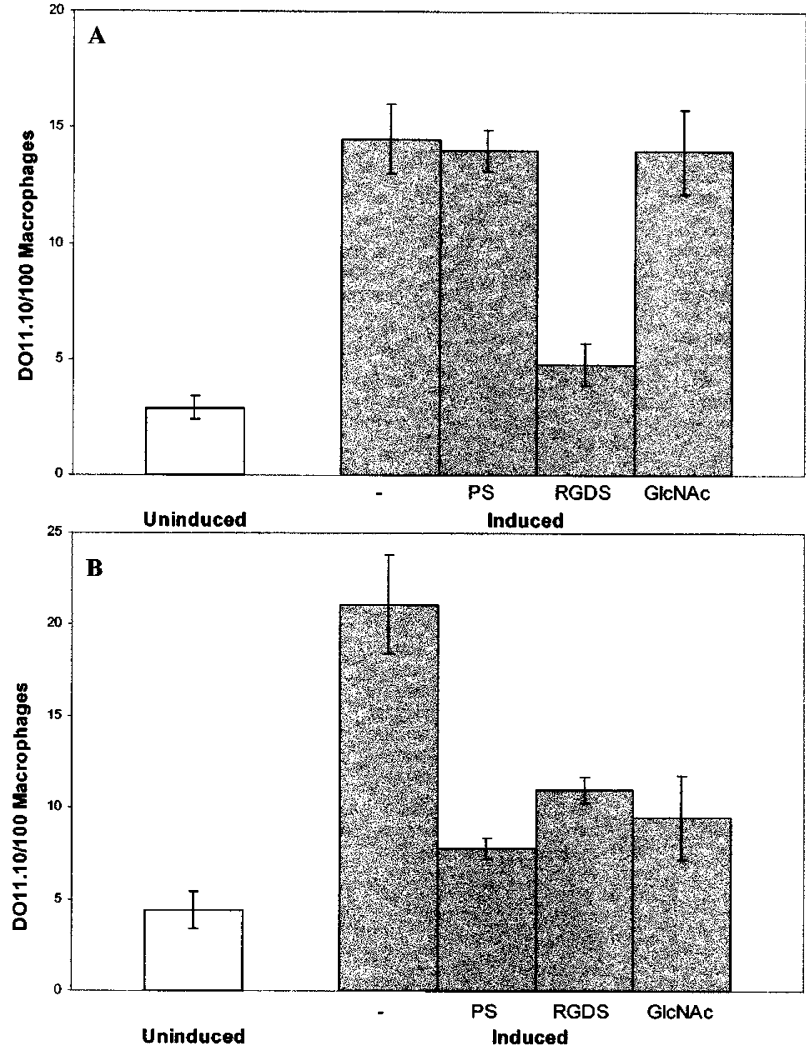

Figure 5 Phagocytosis of D011.10 cells by unactivated or $\beta$-glucanactivated $\mathrm{J} 774$ macrophages in the presence of various inhibitors. DO11.10 cells induced to express PS by incubating with $\mathrm{Ca}^{2+}$ ionophore in the presence of $\mathrm{Ca}^{2+}$ were suspended with PS vesicles (PS), RGDS, or GICNAc and presented to unactivated (A) or $\beta$-glucan activated (B) J774 macrophages. Phagocytosis of uninduced D011.10 cells is shown for comparison. The data presented are representative of three separate experiments with similar results

authentic apoptotic cells to ensure that the results were not peculiar to the model systems employed. DO11.10 cells were induced with dexamethasone to undergo apoptosis and the resulting apoptotic cell populations (see Figure 2B) were presented to unactivated and activated $\mathrm{J} 774$ macrophages. As shown in Figure 7, the phagocytosis of these apoptotic target cells in both cases was inhibited by annexin $\mathrm{V}$ treatment of the macrophages to a level comparable to that observed by masking PS on the surface of the ionophore-treated target cells. Similar experiments were also performed using both primary apoptotic target cells and primary macrophages. Elicited peritoneal macrophages, which express an activated macrophage inhibition phenotype, and which are shown in Figure 2A to expose PS on their surface, were presented with primary murine thymocytes induced by dexamethasone to undergo apoptosis. As shown in Figure 8, the results using primary cells accurately recapitulate the sensitivity to annexin $\mathrm{V}$ seen using cell lines. Together, these results indicate that the sensitivity of the phagocytosis of target cells to annexin $\mathrm{V}$ treatment of the phagocyte is a general property of PS-exposing targets and professional phagocytes.

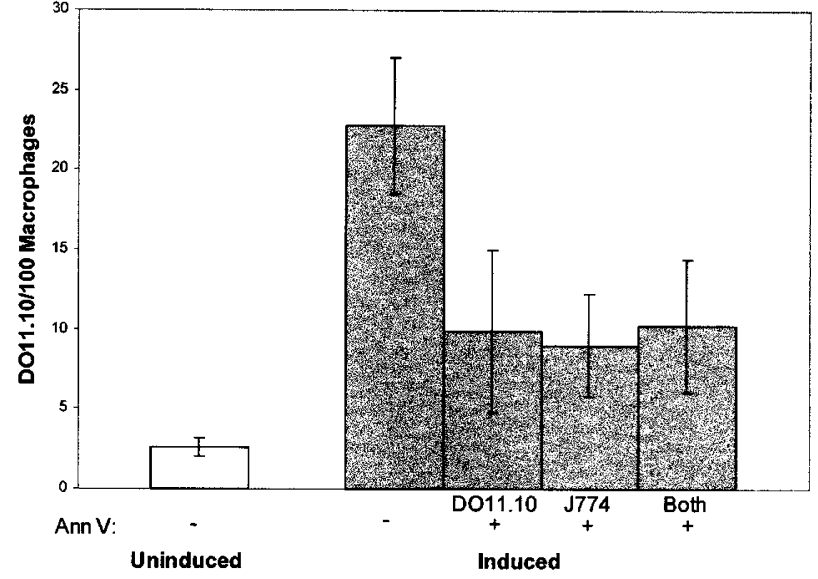

Figure 6 Phagocytosis following pre-treatment of DO11.10 targets, $\beta$ glucan-activated $\mathrm{J} 774$ macrophages, or both cell types with annexin $\mathrm{V}$. D011.10 cells were induced to express PS by incubating with $\mathrm{Ca}^{2+}$ ionophore in the presence of $\mathrm{Ca}^{2+}$. These targets, $\beta$-glucan-activated $\mathrm{J} 774$ macrophages, or both cell types were pre-treated with $10 \mu \mathrm{M}$ annexin $\mathrm{V}$ (Ann V) before presenting the targets to macrophages. When only one cell type was pre-treated, cells were washed before targets were presented to macrophages. Phagocytosis of uninduced D011.10 cells is shown for comparison. The data presented are representative of two separate experiments with similar results
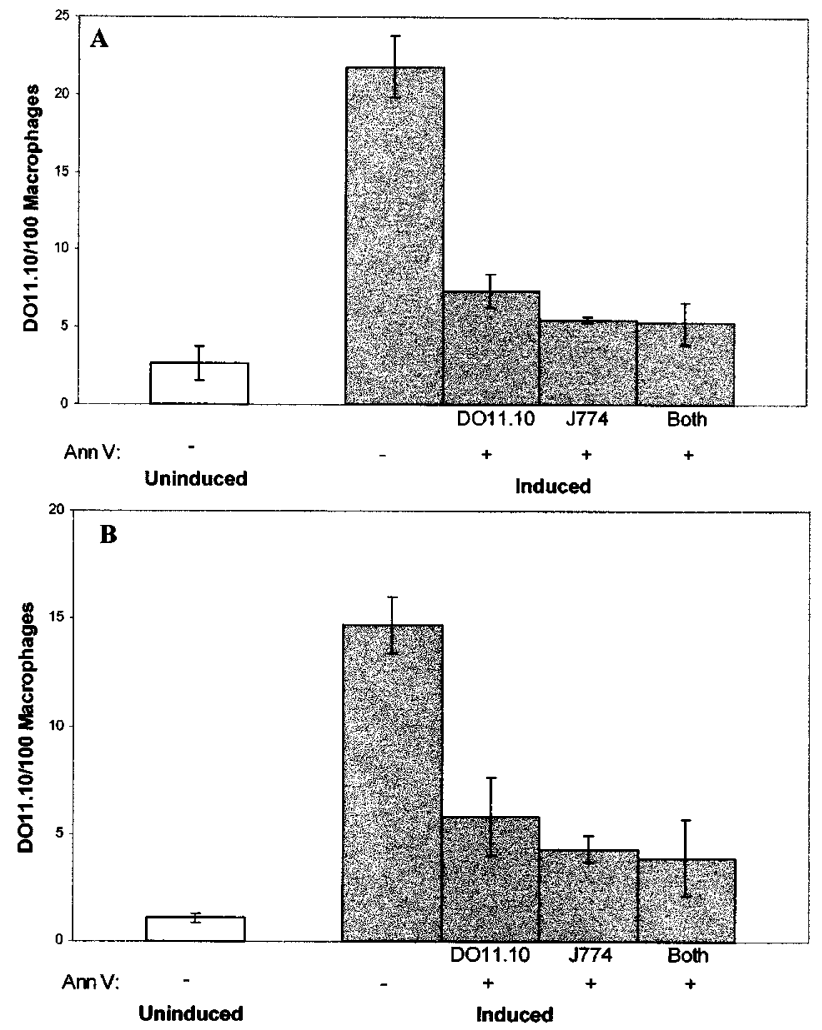

Figure 7 Phagocytosis of apoptotic D011.10 cells by J774 macrophages following pre-treatment with annexin V. D011.10 cells were induced by dexamethasone to undergo apoptosis. These targets, unactivated $(\mathbf{A})$ or $\beta$ glucan-activated (B) J774 macrophages, or both cell types were pre-treated with $10 \mu \mathrm{M}$ annexin $\mathrm{V}$ (Ann V). When only one cell type was pre-treated, cells were washed before targets were presented to macrophages. Phagocytosis of uninduced D011.10 cells is shown for comparison. The data presented are representative of two separate experiments with similar results 


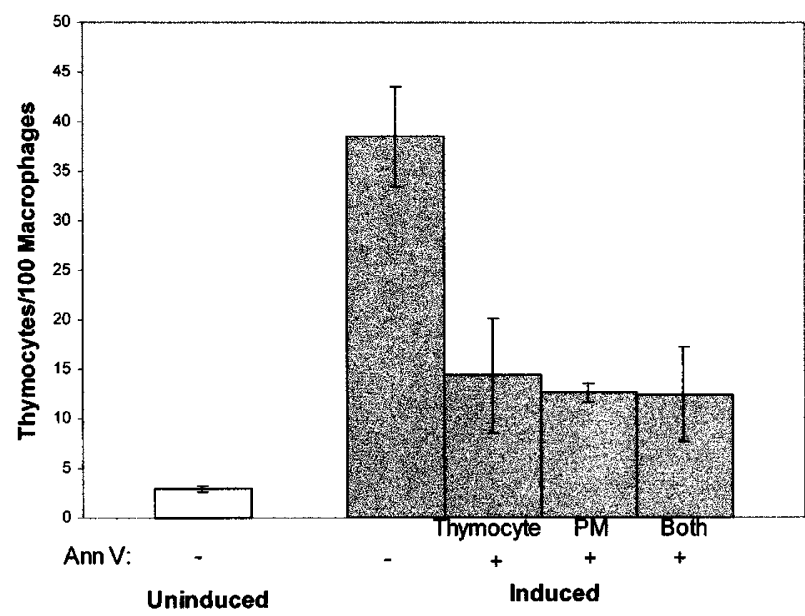

Figure 8 Phagocytosis of apoptotic thymocytes by elicited peritoneal macrophages following pre-treatment with annexin V. Primary thymocytes were induced by dexamethasone to undergo apoptosis. These targets, elicited peritoneal macrophages (PM), or both cell types were pre-treated with $10 \mu \mathrm{M}$ annexin $\mathrm{V}(\mathrm{Ann} \mathrm{V})$. When only one cell type was pre-treated, cells were washed before targets were presented to macrophages. Phagocytosis of uninduced thymocytes is shown for comparison. The data presented are representative of two separate experiments with similar results

\section{Discussion}

Expression of PS on the macrophage surface is at odds with the generalization that normal, non-apoptotic cells restrict PS to the inner leaflet of the plasma membrane. However, organism-wide surveys of cells which bind annexin $\mathrm{V}$ in vivo have already identified exceptions to this general rule, ${ }^{4,27,28}$ including fusing myoblasts and megakaryocytes. Regions of annexin $\mathrm{V}$ binding were also observed on potential phagocytes in brain, clustered near apoptotic targets, and were interpreted as possible sites of membrane exchange. The results presented here suggest alternative possibilities. The staining of macrophages with annexin V and MC540 suggests that PS exposure is constitutive in these cells, and that membrane exchange is thus not required to explain the annexin $\mathrm{V}$ binding observed in vivo. However, the exposure of PS on the macrophages examined here seems to occur over the entire cell surface, suggesting that any concentration of $\mathrm{PS}$ in the region near a potential target, as seen in the in vivo studies, may be an induced redistribution.

Previous studies established that phagocytosis of apoptotic thymocytes by macrophages is sensitive to inhibition by annexin $\mathrm{V}^{6}{ }^{6}$ the studies presented here examine more carefully the site at which annexin $\mathrm{V}$ acts. Given the well-known exposure of PS on apoptotic cells at an early stage in the apoptotic program, there is little drama in the confirmation that binding of annexin $\mathrm{V}$ to the PS exposed at the apoptotic target cell surface inhibits phagocytosis. Much more surprising is the discovery that pre-treating macrophages with annexin $\mathrm{V}$ similarly inhibits phagocytosis. This finding indicates that the PS exposed on the macrophage surface, identified by fluorescent annexin $\mathrm{V}$ staining, plays a functional role in phagocytosis. Because the pre-treatment with annexin $\mathrm{V}$ preceded the addition of target cells, the constitutive expression of PS on the macrophage cell surface is sufficient for its functional activity. Further, the absence of an inhibitory effect of annexin $\mathrm{V}$ on phagocytosis of latex beads or opsonized cells implies that the PS exposed on the macrophage surface is not required for general engulfment processes, such as membrane bending and membrane fusion at the external leaflet, but rather is specific to PS-expressing targets. Since treating both targets and macrophages with annexin $\mathrm{V}$ was no more effective than treating either alone, the PS exposed on each of the target cell and macrophage surfaces must be two elements of the same mechanism. However, why the mechanism requires PS on both target and macrophage, or even whether PS plays the same role at both cell surfaces, is unclear.

The simplest mechanism to explain the dual role of PS is that it serves as a ligand for a divalent molecule that bridges the target and macrophage surfaces. $\mathrm{Ca}^{2+}$ ions might be imagined to play such a role, ${ }^{29,30}$ except that inhibition of phagocytosis by PS is stereospecific, ${ }^{3,7}$ which is not consistent with this simplest model. Bridging between the target and macrophage surface might also occur via a multivalent PS-binding protein. Although attractive, there is no evidence for the existence of such a protein and the fact that phagocytosis occurs within $30 \mathrm{~min}$ after washed targets and macrophages are combined, in the absence of serum, argues against a soluble protein mediating this effect. PS stereospecificity has been taken to mean that a receptor on macrophages recognizes PS on the target cell surface. However, it is not clear whether stereospecificity applies at the macrophage surface, the target cell surface or both. Therefore, it remains possible that a receptor on lymphocytes recognizes PS on the macrophage surface. Although both target and macrophage may possess PS receptors, both of which are required for phagocytosis, it is just as possible that PS on one of the cell surfaces does not act as a ligand, but rather serves some other purpose, such as a co-factor required for the operation of the recognition machinery.

One macrophage membrane protein implicated in the phagocytosis of apoptotic cells is $A B C 1$, a member of the large family of ATP-binding cassette (ABC) ATPases which mediate or regulate the movement of a wide variety of substrates across cell membranes. ${ }^{31,32}$ Treating mouse macrophages with antibodies to $A B C 1$ blocks their ability to phagocytose apoptotic lymphocytes. ${ }^{33}$ In $C$. elegans, the ced-7 gene has been identified as a homolog of $A B C 1$ whose expression is required in both target and engulfing cell for removal of apoptotic cells, ${ }^{34}$ suggesting that CED-7dependent transport of the same molecule is required in both cell types for phagocytosis. Recently, inhibitors of $A B C 1$ were shown to block phagocytosis when applied to either macrophage or apoptotic target, and also block the induced exposure of PS in either cell type. ${ }^{35}$ The apparent requirement for exposure of $P S$ on both macrophage and target for phagocytosis argues that the engulfment role of CED-7 in $C$. elegans or the corresponding ABC-1 protein in mammals stems from its involvement in the pathway leading to the exposure of PS on both the target and macrophage surface. ${ }^{35}$ Externalization of PS in apoptotic lymphocytes results from activation of a non-specific lipid 
flipsite termed the scramblase. ${ }^{16,36} \mathrm{~A} \mathrm{Ca}^{2+}$-dependent lipid scrambling activity has been reconstituted in artificial lipid vesicles with proteins isolated from erythrocytes ${ }^{37}$ and platelets, ${ }^{38}$ and the protein from erythrocytes responsible for this activity cloned. ${ }^{39}$ However, the activity of the reconstituted protein is very low and other proteins may also be involved in PS externalization. ${ }^{39,40}$ Although it appears that CED-7/ABC-1 is involved in PS externalization, ${ }^{27}$ ATP does not seem to be required for the dissipation of membrane phospholipid asymmetry, ${ }^{41}$ leaving open the question of what that involvement might be.

In the studies presented here, several experiments used target cells treated with a $\mathrm{Ca}^{2+}$ ionophore to induce PS exposure, making possible a comparison between these cells and cells on which PS is exposed as a part of the apoptotic program. First, inhibition of uptake when macrophages were treated with annexin $\mathrm{V}$ was equally effective for apoptotic and ionophore-treated targets, implying that loss of asymmetry in the target cell is sufficient to engage the PS-dependent mechanism on the macrophage surface. Second, no marked difference was seen in the inhibitor sensitivity of the uptake of ionophoretreated versus apoptotic targets; RGDS inhibited the phagocytosis of ionophore-treated targets by unactivated macrophages and GlcNAc inhibited the phagocytosis of ionophore-treated targets by activated macrophages. These agents are generally considered to block recognition of apoptotic target cell ligands by an integrin on unactivated macrophages or by a lectin-like receptor on activated macrophages. The fact that these agents block uptake of ionophore-treated targets argues that loss of transbilayer asymmetry and/or exposure of PS on the cell surface is sufficient to generate those ligands and that those ligands develop over a very short period of time. Changes in the fluidity, ordering, and lipid packing of the outer leaflet of the plasma membrane and an increase in surface hydrophobicity accompany loss of asymmetry in erythrocytes ${ }^{42-45}$ and could be involved in the generation of ligands on the lymphocyte surface. Taken together, these results suggest that ionophore-treated thymocytes are a remarkably good model for studying the mechanisms of recognition and phagocytosis of apoptotic cells by macrophages.

To date, all macrophages studied have utilized either the recognition system inhibitable by $\mathrm{PS}$ vesicles and GICNAc or the recognition system inhibitable by lipid-symmetric erythrocytes and RGDS, but not both. ${ }^{7,8}$ In particular, this either/or rule applies to mouse bone marrow macrophages activated by $\beta$-glucan, which convert from one system to the other, acquiring sensitivity to PS vesicles and GIcNAc, but becoming refractile to inhibition by RGDS, even though the vitronectin receptor is still expressed on the activated macrophage surface. ${ }^{26}$ This finding implies that the vitronectin receptor is functionally neutralized on activated macrophages. The experiments presented here show that J774 macrophages activated by $\beta$-glucan can acquire sensitivity to PS vesicles and GlcNAc, and lose their sensitivity to lipid-symmetric erythrocytes (not shown), while retaining their sensitivity to RGDS. This result suggests that the either/or rule does not result from a requirement for neutralization of the vitronectin receptor in order for the PS
vesicle/GlcNAc-sensitive mechanism to become operational. The nature of the switch between these two PSdependent recognition mechanisms, and their relationship to PS exposure on the macrophage surface, remain to be clarified.

\section{Materials and Methods}

\section{Materials}

Dexamethasone, propidium iodide, paraphenylenediamine mounting media, anti-glycophorin A, B (clone E3), bovine serum albumin (BSA), bovine brain $\mathrm{PS}, \mathrm{Ca}^{2+}$ ionophore $\mathrm{A} 23187, \mathrm{PKH} 26$ labeling kit, and $\beta$ glucan from barley were purchased from Sigma Chemical Co. DiffQuik staining reagents were purchased from Baxter. 5-carboxyfluorescein succinimidyl ester (5-FAM) was purchased from Molecular Probes. J774A.1 macrophages, DO11.10 hybridoma cells, and E. coli TG1 containing a plasmid encoding human placental annexin $\mathrm{V}$ (clone pRK6) were purchased from American Type Culture Collection. Fluoresceinated latex beads ( $1 \mu$ in diameter) were purchased from Polyscience.

\section{Animals}

Male CBA/J mice, 4-8 weeks of age, were maintained on food and water ad libitum in accordance with the guidelines of the Institutional Animal Care and Use Committee.

\section{Macrophages}

Macrophages were elicited in the peritoneal cavity of 6-8 week old mice by intraperitoneal injection of $1 \mathrm{ml}$ of $3 \%$ Brewer's thioglycollate media. Cells were harvested 5 days later by peritoneal lavage using $10 \mathrm{ml}$ of ice-cold PBS (7.4 mM Na $2 \mathrm{HPO}_{4}, 2.6 \mathrm{mM} \mathrm{NaH}_{2} \mathrm{PO}_{4}, 137 \mathrm{mM}$ $\mathrm{NaCl}, 10 \mathrm{mM} \mathrm{KCl}$ ) containing $10 \mathrm{U} / \mathrm{ml}$ of heparin. Collected cells were washed in PBS and suspended in RPMI 1640 medium containing 10\% fetal bovine serum (FBS). Approximately $3 \times 10^{5}$ cells were pipetted onto $18 \mathrm{~mm}$ bicarbonate-treated glass coverslips kept in $30 \mathrm{~mm}$ petri dishes. After $2 \mathrm{~h}$ at $37^{\circ} \mathrm{C}$, nonadherent cells were removed by aspiration, and the medium replaced with fresh RPMI 1640 medium containing $10 \%$ FBS. These macrophage cultures were used for phagocytosis assays within $24 \mathrm{~h}$ of plating. J774A.1 macrophages were grown in RPMI 1640 medium supplemented with $10 \%$ FBS at $37^{\circ} \mathrm{C}$ in $5 \% \quad \mathrm{CO}_{2}$. Cultures of $3 \times 10^{5} \mathrm{~J} 774$ macrophages per bicarbonate-treated coverslip or tissue culture well (24 well plate) were prepared within $24 \mathrm{~h}$ prior to phagocytosis assays. J774 macrophages activated by incubating in RPMI 1640 medium plus $10 \%$ FBS and $100 \mu \mathrm{g} / \mathrm{mL}$ of $\beta$-glucan for $3-5$ days were used exactly as unactivated $\mathrm{J} 774$ macrophages for phagocytosis assays.

\section{Thymocytes}

Thymuses were removed from 4-6 week old mice and dissociated in PBS. After collecting cells by centrifugation and resuspending in $17 \mathrm{mM}$ Tris, $140 \mathrm{mM} \mathrm{NH}_{4} \mathrm{Cl}$, pH 7.2, to lyse erythrocytes, thymocytes were washed and resuspended at $10^{7}$ cells $/ \mathrm{ml}$ in RPMI 1640 medium containing 10\% FBS. D011.10 cells were grown in RPMI 1640 medium supplemented with $1 \mathrm{mM}$ sodium pyruvate and $10 \% \mathrm{FBS}$ at $37^{\circ} \mathrm{C}$ in $5 \% \mathrm{CO}_{2}$. Apoptosis was induced in thymocytes $\left(10^{6} \mathrm{cell} / \mathrm{sL}\right)$ or log phase D011.10 (10 cells $/ \mathrm{mL})$ by addition of $10^{-6} \mathrm{M}$ or $5 \times 10^{-6} \mathrm{M}$ dexamethasone, respectively, and incubation at $37^{\circ} \mathrm{C}$ in $5 \% \mathrm{CO}_{2}$ for $6 \mathrm{~h}$. Apoptosis was monitored by fluorescent annexin $\mathrm{V}$ 
staining. To induce PS expression with ionophore, log phase D011.10 cells in RPMI 1640 medium were treated for $10 \mathrm{~min}$ at $37^{\circ} \mathrm{C}$ with either $1 \mathrm{mM} \mathrm{CaCl} 2$ plus $10 \mu \mathrm{g} / \mathrm{ml}$ of the $\mathrm{Ca}^{2+}$ ionophore $\mathrm{A} 23187$ or $1 \mathrm{mM}$ $\mathrm{CaCl}_{2}$ alone as a control. After the appropriate treatment, cells were collected by centrifugation, washed, and resuspended in annexin $\mathrm{V}$ buffer (10 mM HEPES/NaOH, pH 7.4, $140 \mathrm{mM} \mathrm{NaCl}, 2.5 \mathrm{mM} \mathrm{CaCl}_{2}$ ).

\section{Phagocytosis assays}

$10^{6}$ thymocytes or D011.10 cells in $150 \mu \mathrm{l}$ of annexin $\mathrm{V}$ buffer were overlayed onto coverslip cultures of $3 \times 10^{5}$ macrophages prepared as described above. When appropriate, either the target cells or macrophages were first incubated in $150 \mu \mathrm{L}$ of various concentrations of annexin $\mathrm{V}$ in annexin $\mathrm{V}$ buffer for $15 \mathrm{~min}$ at room temperature and then washed twice with annexin $\mathrm{V}$ buffer before targets in $150 \mu \mathrm{L}$ of annexin $\mathrm{V}$ buffer were overlayed onto macrophages. When both targets and macrophages were pretreated with annexin $\mathrm{V}$, neither was washed prior to overlaying. In some experiments target cells resuspended in annexin $\mathrm{V}$ buffer were mixed in a total volume of $150 \mu \mathrm{L}$ with either $7.5 \mathrm{nM}$ PS vesicles prepared as previously described, ${ }^{8} 1 \mathrm{mM}$ RGDS, or $20 \mathrm{mM}$ GlcNAc, immediately before being overlayed onto macrophages. After $30 \mathrm{~min}$ at $37^{\circ} \mathrm{C}$ in $5 \% \mathrm{CO}_{2}$, coverslips were washed vigorously in PBS and fixed in $1.8 \%$ formaldehyde for $15 \mathrm{~min}$ before staining with Diff-Quik. Cells were counted as phagocytosed as previously described in detail. ${ }^{8}$ Results are presented as the mean \pm standard deviation of triplicate coverslips. Each experiment was performed at least twice with similar results. For phagocytosis of fluorescent latex beads, beads were washed twice in RPMI 1640 medium and diluted 10000 fold in annexin V buffer, then $100 \mu \mathrm{l}$ was added to $3 \times 10^{5}$ macrophages per well of a 24-well tissue culture plate that either had or had not been pretreated for $10 \mathrm{~min}$ with $200 \mu \mathrm{L}$ of either $1 \mu \mathrm{M}$ annexin $\mathrm{V}$ or BSA at room temperature. After $30 \mathrm{~min}$ at $37^{\circ} \mathrm{C}$ in $5 \% \mathrm{CO}_{2}$, macrophages were washed and released from the dishes with $0.5 \mathrm{mM}$ EDTA in PBS and analyzed by flow cytometry. For Fc-mediated phagocytosis, erythrocytes from fresh venous blood obtained from volunteers according to institutional guidelines were first labeled with the fluorescent dye $\mathrm{PKH} 26$ according to the manufacturer's instructions. Briefly, $50 \mu \mathrm{L}$ of packed erythrocytes were resuspended in $500 \mu \mathrm{L}$ of diluent $\mathrm{C}$. PKH26 dye was added to $2 \mu \mathrm{M}$ and incubated for $4 \mathrm{~min}$ at room temperature with constant shaking followed by the addition of $500 \mu \mathrm{L}$ of human serum for $1 \mathrm{~min}$ to terminate labeling. Cells were washed and then treated with a $1: 400$ dilution of anti-glycophorin monoclonal antibody in PBS for $15 \mathrm{~min}$ at room temperature. Opsonized cells were washed and resuspended at $10^{7}$ cells $/ \mathrm{mL}$ in annexin $\mathrm{V}$ buffer. One hundred and fifty $\mu \mathrm{L}$ of this cell suspension was added to $3 \times 10^{5}$ macrophages per well of a 24-well tissue culture plate that were pre-treated with $200 \mu \mathrm{L}$ of either $1 \mu \mathrm{M}$ annexin $\mathrm{V}$ or BSA for $15 \mathrm{~min}$ at room temperature. After $30 \mathrm{~min}$ at $37^{\circ} \mathrm{C}$ in $5 \% \mathrm{CO}_{2}$, the medium was removed by aspiration and cultures were treated with $17 \mathrm{mM}$ Tris, $140 \mathrm{mM} \mathrm{NH}_{4} \mathrm{Cl}, \mathrm{pH} \mathrm{7.2,} \mathrm{to} \mathrm{lyse} \mathrm{uningested} \mathrm{cells.} \mathrm{Macrophages}$ were removed from the wells with $0.5 \mathrm{mM}$ EDTA in PBS and analyzed by flow cytometry.

\section{Preparation of fluorescent annexin V}

Recombinant human placental annexin $V$ was expressed in $E$. coli and purified as described previously. ${ }^{6,46}$ Purified annexin $\mathrm{V}$ at $15 \mathrm{mg} / \mathrm{ml}$ was dialyzed overnight into $1.0 \mathrm{M}$ sodium bicarbonate buffer, $\mathrm{pH} 8.5$. One $\mathrm{mg}$ of a freshly prepared stock solution of 5-FAM dissolved in dimethylformamide at $1 \mathrm{mg} / \mathrm{ml}$ was added to $10 \mathrm{mg}$ of purified annexin V. Following incubation for $1 \mathrm{~h}$ at room temperature with shaking, unconjugated dye was removed by dialysis overnight into fresh sodium bicarbonate buffer.

\section{Fluorescent annexin V staining}

$10^{6}$ thymocytes or D011.10 cells were incubated with $1 \mu \mathrm{g}$ of fluorescent annexin $V$ for $15 \mathrm{~min}$ at room temperature in $100 \mu \mathrm{L}$ of annexin $\mathrm{V}$ buffer and then brought to $500 \mu \mathrm{L}$ with annexin $\mathrm{V}$ buffer for flow cytometry. For flow cytometric analysis of macrophages, $10^{6}$ cells removed from monolayer by scraping were stained as described above except that incubation was performed on ice and annexin $\mathrm{V}$ dilution buffer was ice-cold. For fluorescent microscopy, $3 \times 10^{5}$ macrophages in monolayer culture on bicarbonate-treated glass coverslips were incubated with $1 \mu \mathrm{g}$ of fluorescent annexin $\mathrm{V}$ for $15 \mathrm{~min}$ at $4^{\circ} \mathrm{C}$ in $150 \mu \mathrm{L}$ of annexin $\mathrm{V}$ buffer. After staining, the cultures were washed three times with ice-cold annexin $\mathrm{V}$ buffer, fixed in $2 \%$ formaldehyde for $15 \mathrm{~min}$ and mounted in $90 \%$ glycerol containing $0.1 \mathrm{mg} / \mathrm{mL}$ of paraphenylenediamine, to inhibit fading, in PBS. ${ }^{47}$

\section{Microscopy}

Annexin V-stained cells were examined using a Zeiss Axioplan fluorescence microscope. Images were captured with a Spot 2 camera (Diagnostic Instruments) and recorded using Adobe Photoshop.

\section{Flow cytometry}

A minimum of 10000 cells/sample was analyzed using an EPICS-XLMCL flow cytometer (Coulter Electronics, Hialeah, FL, USA) fitted with a single $15 \mathrm{~mW}$ argon ion laser providing excitation at $488 \mathrm{~nm}$. Annexin V staining was monitored through a $525 \mathrm{~nm}$ bandpass filter; propidium iodide was added at $10 \mu \mathrm{g} / \mathrm{mL}$ immediately prior to analysis and cells stained by the dye were gated out of profiles. Macrophages phagocytosing PKH26-labeled opsonized erythrocytes or fluorescent latex beads were monitored through a $575 \mathrm{~nm}$ bandpass filter.

\section{Acknowledgements}

Supported by the United States National Science Foundation. We thank Elaine Kunze for help with flow cytometry, Davis $\mathrm{Ng}$ and Eric Spear for help with immunofluorescence microscopy, and Michael Earley for valuable discussions.

\section{References}

1. Wyllie AH, Kerr JFR and Currie AR (1980) Cell death: the significance of apoptosis. Int. Rev. Cytol. 68: 251-306

2. Ellis RE, Yuan J and Horvitz HR (1991) Mechanisms and functions of cell death. Ann. Rev. Cell Biol. 7: 663-698

3. Fadok VA, Voelker DR, Campbell PA, Cohen JJ, Bratton JL and Henson PM (1992) Exposure of phosphatidylserine on the surface of apoptotic lymphocytes triggers specific recognition and removal by macrophages. J. Immunol. 148: 2207-2216

4. Van den Eijnde SM, Boshart L, Reutelingsperger CPM, De Zeeuw $\mathrm{Cl}$ and Vermeij-keers C (1997) Phosphatidylserine plasma membrane asymmetry: a pancellular phenomenon which alters during apoptosis. Cell Death Differ. 4: $311-316$

5. Bennett MR, Gibson DF, Schwartz SM and Tait TF (1995) Binding and phagocytosis of apoptotic vascular smooth muscle cells is mediated in part by exposure of phosphatidylserine. Circ. Res. 77: 1136-1142 
6. Krahling S, Callahan MK, Williamson P and Schlegel RA (1999) Exposure of phosphatidylserine is a general feature in the phagocytosis of apoptotic lymphocytes by macrophages. Cell Death Differ. 6: 183-189

7. Fadok VA, Savill JS, Haslett C, Bratton DL, Doherty DE, Campbell PA and Henson PM (1992) Different populations of macrophages use either the vitronectin receptor or the phosphatidylserine receptor to recognize and remove apoptotic cells. J. Immunol. 149: 4029-4035

8. Pradhan D, Krahling S, Williamson P and Schlegel RA (1997) Multiple systems for recognition of apoptotic lymphocytes by macrophages. Mol. Biol. Cell 8: 767778

9. Pradhan D, Williamson P and Schlegel RA (1994) Phosphatidylserine vesicles inhibit phagocytosis of erythrocytes with a symmetric transbilayer distribution of phospholipids. Mol. Memb. Biol. 11: 181-188

10. Duvall E, Wyllie AH and Morris RG (1985) Macrophage recognition of cells undergoing programmed cell death (apoptosis). Immunol. 56: 351-358

11. Fadok VA, Warner ML, Bratton DL and Henson PM (1998) CD36 is required for phagocytosis of apoptotic cells by human macrophages that use either a phosphatidylserine receptor or the vitronectin receptor. J. Immunol. 161:6250 6257

12. Devitt A, Moffatt OD, Raykundalia C, Capra JD, Simmons DL and Gregory CD (1998) Human CD14 mediates recognition and phagocytosis of apoptotic cells. Nature 392: 505-509

13. Schlegel RA, Krahling S, Callahan MK and Williamson P (1999) CD14 is a component of multiple recognition systems used by macrophages to phagocytose apoptotic lymphocytes. Cell Death Differ. 6: 583-592

14. Moffat OD, Devitt A, Bell ED, Simmons DL and Gregory CD (1999) Macrophage recognition of ICAM-3 on apoptotic leukocytes. J. Immunol. 162: 6800-6810

15. Williamson $P$ and Schlegel RA (1994) Back and forth: the regulation and function of transbilayer phospholipid movement in eukaryotic cells (Review). Mol. Memb. Biol. 11: 199-216

16. Verhoven B, Schlegel RA and Williamson P (1995) Mechanisms of phosphatidylserine exposure, a phagocyte recognition signal, on apoptotic $T$ lymphocytes. J. Exp. Med. 82: 1597-1601

17. Koopman G, Reutelingsperger CPM, Kuijten GAM, Keehnen RMJ, Pals ST and van Oers HJ (1994)Annexin V for flow cytometric detection of phosphatidylserine on $B$ cells undergoing apoptosis. Blood 84: 1415-1420

18. Williamson P, Mattocks $K$ and Schlegel RA (1983) Merocyanine 540: A fluorescent probe sensitive to lipid packing. Biochim. Biophys. Acta 732: 387393

19. Williamson P, Bateman J, Kozarsky K, Mattocks K, Hermanowitz N, Choe HR and Schlegel RA (1982) Involvement of spectrin in the maintenance of erythrocyte membrane phase state. Cell 30: 725-733

20. McEvoy L, Williamson P and Schlegel RA (1986) Membrane phospholipid asymmetry as a determinant of erythrocyte recognition by macrophages. Proc. Natl. Acad. Sci. USA 83: 3311-3315

21. McEvoy L, Schlegel RA, Williamson P and Del Buono BJ (1988) Merocyanine 540 as a flow cytometric probe of membrane lipid organization in leukocytes. J. Leuk. Biol. 44: 337-344

22. Schlegel RA, Stevens M, Lumley-Sapanski K and Williamson P (1993) Altered lipid packing identifies apoptotic thymocytes. Immunol. Lett. 36: 283-288

23. Mower DA, Peckham DW, Illera VA, Fishbaug JK, Stunz LI and Ashman RF (1994) Decreased membrane phospholipid packing and decreased cell size precede DNA cleavage in mature mouse B cell apoptosis. J. Immunol. 152: $4832-4842$

24. Schlegel RA and Williamson $P$ (1988) Role of phospholipid asymmetry in cellular membrane fusion. In Molecular Mechanisms of Membrane Fusion, Ohki S, Doyle D, Flanagan TD, Hui SE and MayhewE, eds (New York, Plenum Press) pp. 289 301

25. Verhoven B, Krahling S, Schlegel RA and Williamson P (1999) Regulation of phosphatidylserine exposure and phagocytosis of apoptotic T lymphocytes. Cell Death Differ. 6: 262-270

26. Fadok VA, Laszlo DJ, Noble PW, Weinstein L, Riches DWH and Henson PM (1993) Particle digestibility is required for induction of the phosphatidylserine recognition mechanism used by murine macrophages to phagocytose apoptotic cells. J. Immunol. 151: 4274-4285
27. Van den Eijnde SM, Luijsterburg AJM, Boshart L, Vermeij-Keers C Reutelingsperger CPM and De Zeeuw $\mathrm{Cl}$ (1997) In situ detection of apoptosis during embryogenesis with annexin $\mathrm{V}$ : from whole mount to ultrastructure. Cytometry 29: 313-320

28. Van den Eijnde SM, Lips J, Boshart L, Vermeij-Keers C, Reutelingsperger CPM and De Zeeuw $\mathrm{Cl}$ (1999) Spatiotemporal distribution of dying neurons during early mouse development. Eur. J. Neurosci. 11:712-724

29. Papahadjopoulos D, Poste G, Schaeffer BE and Vail WJ (1974) Membrane fusion and molecular segregation in phospholipid vesicles. Biochim. Biophys. Acta 352: 10-28

30. Papahadjopoulos D, Vail WJ, Panghorn WA and Post G (1976) Studies on membrane fusion. II. Induction of fusion in pure phospholipid membranes by calcium and other divalent metals. Biochim. Biophys. Acta 448: 265-283

31. Doige CA and Ames CF-L (1993) ATP-dependent transport systems in bacteria and humans: relevance to cystic fibrosis and multidrug resistance. Ann. Rev. Microbiol. 47: 291-319

32. Higgins CF (1992) ABC transporters: from microorganisms to man. Ann. Rev. Cell Biol. 8: $67-113$

33. Luciani M and Chimini G (1996) The ATP binding cassette transporter ABC1, is required for the engulfment of corpses generated by apoptotic cell death. EMBO J. 15: $226-235$

34. Wu Y and Horvitz HR (1998) The C. elegans cell corpse engulfment gene ced-7 encodes a protein similar to $A B C$ transporters. Cell 93: 951-960

35. Marguet D, Luciani M-F, Moynault A, Williamson P and Chimini G (1999) Engulfment of apoptotic cells involves the redistribution of membrane phosphatidylserine on phagocyte and prey. Nature Cell Biol. 1: 454-456

36. Bratton DL, Fadok VA, Richter DA, Kailey JM, Guthrie LA and Henson PM (1997) Appearance of phosphatidylserine on apoptotic cells requires calcium-mediated nonspecific flip-flop and is enhanced by loss of the aminophospholipid translocase. J. Biol. Chem. 272: 26159-26165

37. Basse F, Stout JG, Sims PJ and Wiedmer T (1996) Isolation of an erythrocyte membrane protein that mediates $\mathrm{Ca}^{2+}$-dependent transbilayer movement of phospholipid. J. Biol. Chem. 271: 17205-17210

38. Comfurius P, Williamson P, Smeets EF, Schlegel RA, Bevers EM and Zwaal RFA (1996) Reconstitution of phospholipid scramblase activity from human blood platelets. Biochemistry 35: 7631-7634

39. Zhou Q, Ahzo J, Stout JG, Luhm RA, Wiedmer T and Sims PJ (1997) Molecular cloning of human plasma membrane phospholipid scramblase. J. Biol. Chem. 272: $18240-18244$

40. Stout JG, Basse F, Luhm RA, Weiss HJ, Wiedmer T and Simms PJ (1997) Scott Syndrome erythrocytes contain a membrane protein capable of mediating $\mathrm{Ca}^{2+}$ dependent transbilayer migration of membrane phospholipids. J. Clin. Invest. 99: $2232-2238$

41. Verhoven B, Schlegel RA and Williamson P (1992) Rapid loss and restoration of lipid asymmetry by different pathways in resealed erythrocyte ghosts. Biochim. Biophys. Acta 1104: 15-23

42. Tanaka Kl and Ohnishi SI (1976) Heterogeneity in the fluidity of intact erythrocyte membranes and its homogenization upon hemolysis. Biochim. Biophys Acta 426: $218-231$

43. Seigneuret M, Zachowski A, Hermann A and Devaux PF (1984) Asymmetric lipid fluidity in human erythrocyte membranes: new spin label evidence. Biochemistry 23: $4271-4275$

44. Williamson P, Algarin L, Bateman J, Choe H-R and Schlegel RA (1985) Phospholipid asymmetry in human erythrocyte ghosts. J. Cell. Physiol. 123: 209-214

45. Morot G, Cribier S, Devaux PF, Geldwerth D, Davoust J, Bureau JF, Fellmann P, Herve $P$ and Frilley $B$ (1986) Asymmetric lateral mobility of phospholipids in the human erythrocyte membrane. Proc. Natl. Acad. Sci. USA 83: 6863-6867

46. Burger A, Berendes R, Voges D, Huber R and Demange P (1993) A rapid and efficient purification method for recombinant annexin $\mathrm{V}$ for biophysical studies. FEBS Lett. 329: 25-28

47. Johnson DG and Nogueira Araujo GM (1981) A simple method of reducing the fading of immunofluorescence during microscopy. J. Immunol. Methods 43 $349-350$ 